\title{
Renewable energy plants: environmental compatibility and external costs assessment at global, regional and local scale
}

\author{
E. Brizio ${ }^{1}$, G. Genon ${ }^{2}$, F. Becchis ${ }^{3,4}$ and D. Russolillo ${ }^{4}$ \\ ${ }^{1}$ Environmental Protection Agency of Piedmont, Via Vecchia di Borgo San Dalmazzo 11, 12100 Cuneo (Italy) \\ Phone number:+0039 0171 329266, e-mail: e.brizio@arpa.piemonte.it \\ ${ }^{2}$ Department DITAG, Politecnico di Torino, Corso Duca degli Abruzzi 24, 10129 Torino (Italy) \\ ${ }^{3}$ POLIS Department, Università del Piemonte Orientale, Via Cavour 84, 15121 Alessandria (Italy) \\ ${ }^{4}$ Fondazione per l'Ambiente “T. Fenoglio", Via Pomba 23, 10123 Torino (Italy)
}

\begin{abstract}
In Italy and many European countries energy production from biomass is encouraged by strong economic subsidies (in Italy up to $280 € / M W h$ granted through a feed-in tariff linked to the electrical production) so that biomass energy plants are getting large diffusion. Nevertheless, this kind of energy plant can involve heavy $\mathrm{PM}_{10}$, NOx, ammonia, methane and $\mathrm{N}_{2} \mathrm{O}$ emissions, as well as indirect emissions relating to cultivation, transport, fertilizers' production. Within the described outline, the definition of the environmental compatibility as well as technological and economic issues dealing with the emerging renewable energy scenario is of primary importance. This evaluation should take into account global parameters as well as environmental impacts at regional and local scale coming from new polluting emissions. The environmental balances regarding new energy plants are of primary importance within very polluted areas such as Northern Italy where air quality limits are systematically exceeded. The paper analyses the energy and environmental performances of anaerobic co-digestion of manure and energy crops, wood and poultry manure combustion, involving the emissive balances, analysing different possible energy scenarios, using environmental economics tools like the ExternE methodology, an approach devoted to the assessment of the externalities associated to airborne pollution. The most important conclusion that can be drawn is that the production of renewable energy from anaerobic digestion, can strongly increase ammonia and NOx emissions and, in some cases, also GHG emissions could be worrying, whereas the application of best available
\end{abstract}

techniques to waste gas cleaning and energy recovery allows positive environmental balances.

\section{Key words}

Anaerobic digestion, subsidies, NOx, ammonia, environmental balances, energy efficiency, biomass.

\section{Introduction}

Air quality of Northern Italy is between the worst ones of the world, almost certainly the worst one in Europe, due to the strong human activities and the orography of its territory. $\mathrm{PM}_{10}, \mathrm{NO}_{2}$ and ozone concentrations measured at the ground level diffusely and permanently go beyond the quality standards, involving strong and worryingly negative health effects. In particular, $\mathrm{PM}_{10}$ concentration is only partly due to particulate primary emissions: secondary particles (deriving from $\mathrm{NOx}, \mathrm{SOx}, \mathrm{NH}_{3}$ and VOC) account for $60-70 \%$ of total PM concentration (Giugliano \& Lonati [1]). Moreover, some European studies report (De Leeuw [2]) the following aerosol formation factors, to be considered by weight, starting from gaseous pollutants: NOx 0,88 (that is, $88 \%$ of emitted NOx become PM within the atmosphere); $\mathrm{SOx} 0,54 ; \mathrm{NH}_{3} 0,64$. In order to control and improve air quality in Northern Italy, the emissions of gaseous compounds such as NOx and ammonia (mostly emitted by agricultural sector) should be reduced substantially. Another strong environmental critical issue of Northern Italy is nitrate contamination of surface and ground-water resources mainly due to the use of fertilizers and the land-spreading of animal manures. The described critical state of air quality sets a potential trade-off between air quality policies and renewable energy policies, as showed in the following chapters. 
In our analysis we have been focusing on an interdisciplinary approach in order to perform integrated assessments that take into account technological issues, emission scenarios and economic and financial issues from both the private and public point of view, the latter thanks to the full implementation of externalities in our model. Yet it is very important to underline that an unique model of analysis for the mentioned trade-off (air quality policy vs. renewable policy) is far from being within close reach because, especially when CHP or any other multi-product energy system is in place, the allocation of private costs and environmental externality is arbitrary [5]. Nonetheless it is important to produce robust hypothesis and scenarios in order to give policy makers a coherent framework within which informed decisions can be taken.

In our case studies the structure of the analysis starts from the assessment of the local availability of the biofuel taken into consideration, followed by an analysis of the energy demand (both electrical and thermal) and an assessment of the Best Available Techniques for both the energy production system and the chain of abatement systems for airborne pollutants. When the technological framework is ready, the integrated technical-economic analysis starts, taking into consideration the private and social costs and benefits associated to the life cycle of the energy system. Usually two different discount rates are applied to the private and social cash flows in order to calculate the net present values and other indices for each one of them: $5 \%$ is the discount rate we applied to direct market costs and benefits and $3.5 \%$ is the value we used to discount external costs and benefits during the plant lifetime.

\section{Emissions from renewable energy plants}

As far as specific emissions of NOx are concerned, Figure 1 reports the comparison between the most frequent renewable energy technologies (the four at the top of the plot) and some fossil fuel energy plants (Natural Gas - NG - turbines and reciprocating engines); these data are taken from existing plant performances, so that their reliability is very satisfying. As one can easily observe, renewable energy plants, unless they are equipped with efficient abatement devices, generally cause higher NOx emissions, twice/three times and up to a hundred times more than traditional energy plants burning natural gas, the most common fuel for new business as usual settlements in Italy. Similar remarks could be done for PM emissions from solid biomass combustion and VOC due to biogas or vegetable oil burned by engines. In spite of their impacting potential, it's very difficult to impose abatement systems (catalytic oxidation, SCR, SNCR, air/fuel staging, etc..) that could mitigate the impacts and one of the reason is due to the fact that renewable energy plants in Italy undergo very fast authorizing procedures (they are defined as public utility systems, not postponable and urgent). Nevertheless, emissions from renewable energy plants could be counterbalanced by means of cogeneration and replacement of existing thermal plants; unfortunately, cogeneration is often disregarded because, thanks mainly to subsidies (the most common of them are renewable energy certificates - so called green certificates - and feed-in tariffs of 280 Euro/MWh for systems up to $1 \mathrm{MW}$ of power capacity), all the business is focused only on electricity production and consequently the emissive balance could become strongly negative at the local scale.

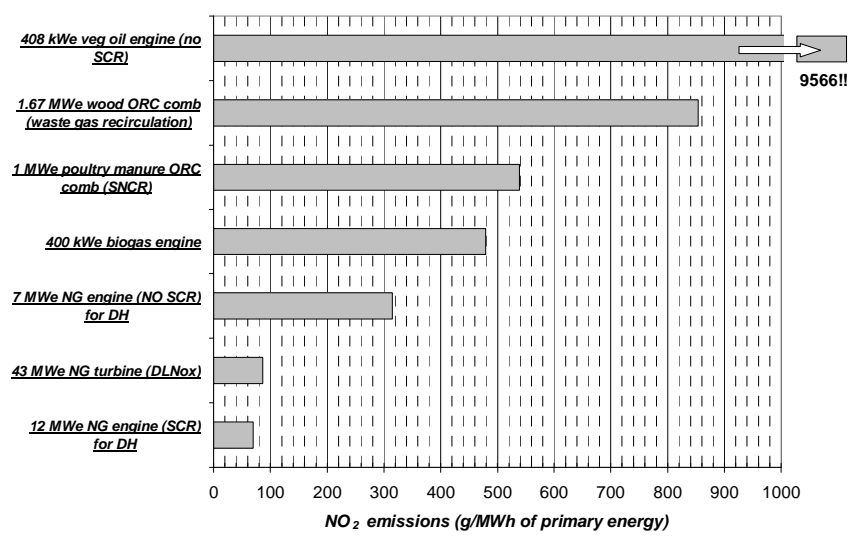

Fig. 1. $\mathrm{NO}_{2}$ emissions for fossil and renewable energy plants

\section{Case study 1: Anaerobic Digestion/biogas}

Anaerobic digestion (AD) of animal manure can be an answer to odour nuisance but it is totally ineffective on nitrogen content of digested materials; moreover, also $\mathrm{CH}_{4}$ and $\mathrm{N}_{2} \mathrm{O}$ could be enhanced with respect to the ante operam conditions. Due to obvious economic drivers, manure is often digested together with energy crops such as maize, triticale and sorghum in order to increase the volatile solid (VS) content and then biogas production (with higher energy quality coming from higher methane yields).

Within anaerobic digesters, a large part of nitrogen contained in proteins is hydrolyzed to ammonium ion $\left(\mathrm{NH}_{4}{ }^{+}\right)$and dissolved ammonia $\left(\mathrm{NH}_{3}\right)$ that can be volatilized; an increase in $\mathrm{pH}, \mathrm{NH}_{3}$ concentration and temperature, three conditions that do occur after anaerobic digestion, enhance ammonia emissions during storage and after field application. Moreover, nitrogen content of the mixture to be digested is strongly increased by the use of energy crops (for example, maize silage contain $4.3 \mathrm{~kg}$ N/ton of fresh matter). This way, the nitrogen amount to be managed along with digested materials can be strongly larger than that in primary manure and it is surely more suitable for volatilization. Based on reliable emission factors it is possible to assess that at least $34 \pm 11 \%$ of nitrogen contained in the digested materials is emitted as $\mathrm{NH}_{3}-\mathrm{N}$ from the storage and land-spreading (almost $15 \%$ from the landspreading). We should also consider NOx emissions coming from the internal combustion engines that recover the energy from the biogas_production $(\approx 500 \mathrm{~g}$ $\mathrm{NO}_{2}$ /MWh of primary energy).

The emissions from a standard $\mathrm{AD}$ plant digesting manure and energy crops (50/50 by weight) can be also seen as a specific emission of secondary PM around 4 $\mathrm{g} / \mathrm{kWh}_{\mathrm{el}}$ due to energy production from $\mathrm{AD}$, whereas the average secondary PM emission factor for the Italian national power system $\left(\mathrm{SO}_{2}: 0,67 \mathrm{~g} / \mathrm{kWh}_{\mathrm{el}}\right.$; $\mathrm{NOx}: 0,523$ 
$\left.\mathrm{g} / \mathrm{kWh}_{\mathrm{el}} ; \quad \mathrm{PM}: \quad 0,024 \mathrm{~g} / \mathrm{kWh}_{\mathrm{el}}\right)$ is $0,85 \mathrm{~g} / \mathrm{kWh}_{\mathrm{el}}$. As obvious, the reported figures refer to plants without any ammonia or NOx abatement devices, that would be considered as Best Available Techniques but that are generally not planned for new installations due to market costs and the inexistence of a strong obligation framework, so the emissive balance at the local and regional scale could be strongly negative for the described renewable technology.

As far as greenhouse gases balances are concerned, the so called post-methanation potential, depending on VS content, and $\mathrm{N}_{2} \mathrm{O}$ emissions from the storage of digested materials should be considered. This way, taking into account the VS removal efficiency of $\mathrm{AD}$, often lower than $50 \%$, the methanation potential found through several experiments and consistent emission factors for $\mathrm{N}_{2} \mathrm{O}$ (see also IPCC standards), a proper GHG balances can be developed as reported in Figure 2, according to 5 different scenarios.

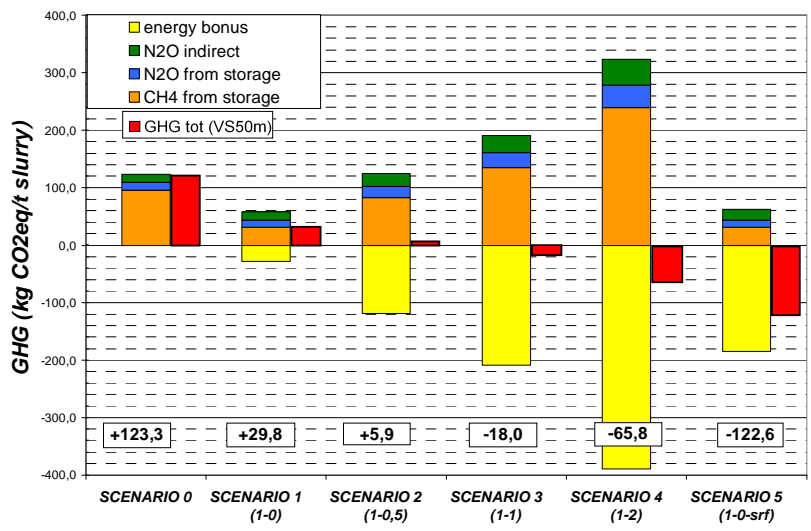

Fig. 2. GHG balance. SCENARIO 0: manure as usual (storage+land spreading); SCENARIO 1-4 (anaerobic digestion of manure and maize): in brackets $\mathrm{t}$ manure $/ \mathrm{h}-\mathrm{t}$ maize $/ \mathrm{h}$ fed to digesters; SCENARIO 5: anaerobic digestion of manure alone $(1 \mathrm{t} / \mathrm{h})$ and combustion of poplar wood from SRF cultivated instead of maize in the same area required by scenario 3 ( $1 \mathrm{t}$ of maize/h)

The figures point out that co-digestion of manure and energy crops (when energy crops represent from 30 to $70 \%$ of feedstock), causes indirect GHG emissions (400 $\pm 67 \mathrm{~g} \mathrm{CO}_{2 \mathrm{eq}} / \mathrm{kWh}_{\mathrm{el}}$, mainly due to $\mathrm{CH}_{4}$ releases from the storage of digestate, see also [3]) that nullify the "energy bonus" due to $\mathrm{CO}_{2}$ avoided emissions (in Italy the latest official data available from the Transmission System Operator [6] declare $485 \mathrm{~g} \mathrm{CO}_{2}$ per $\mathrm{kWh}$ of total gross electricity production and $581 \mathrm{~g} \mathrm{CO}_{2}$ per $\mathrm{kWh}$ of solely thermo-electric production, both associated to 2006); in other words, in the case the energy bonus, that is strongly economically propelled, is cancelled by uncontrolled released, the renewable energy mission of $\mathrm{AD}$ would be betrayed. Furthermore, it should be said that the proposed balances neglect the emissions of $\mathrm{CH}_{4}$ and $\mathrm{N}_{2} \mathrm{O}$ from the biogas engine, as well as methane releases from digesters and pressure valves and $\mathrm{CO}_{2 \mathrm{eq}}$ emissions relating to cultivation and transport of energy crops; these contributions would even worsen the reported GHG balances.

\section{Case study 2: combustion of poultry manure}

Direct combustion of poultry manure is supported by a reliable technology, it can produce combined heat and power in a efficient way (overall efficiency up to $80 \%$ ), the atmospheric emissions can be reduced and minimized by modern cleanup devices, the ash is stable, sterile, easier to handle and transport and more marketable as an organic fertiliser than conventional poultry litter.

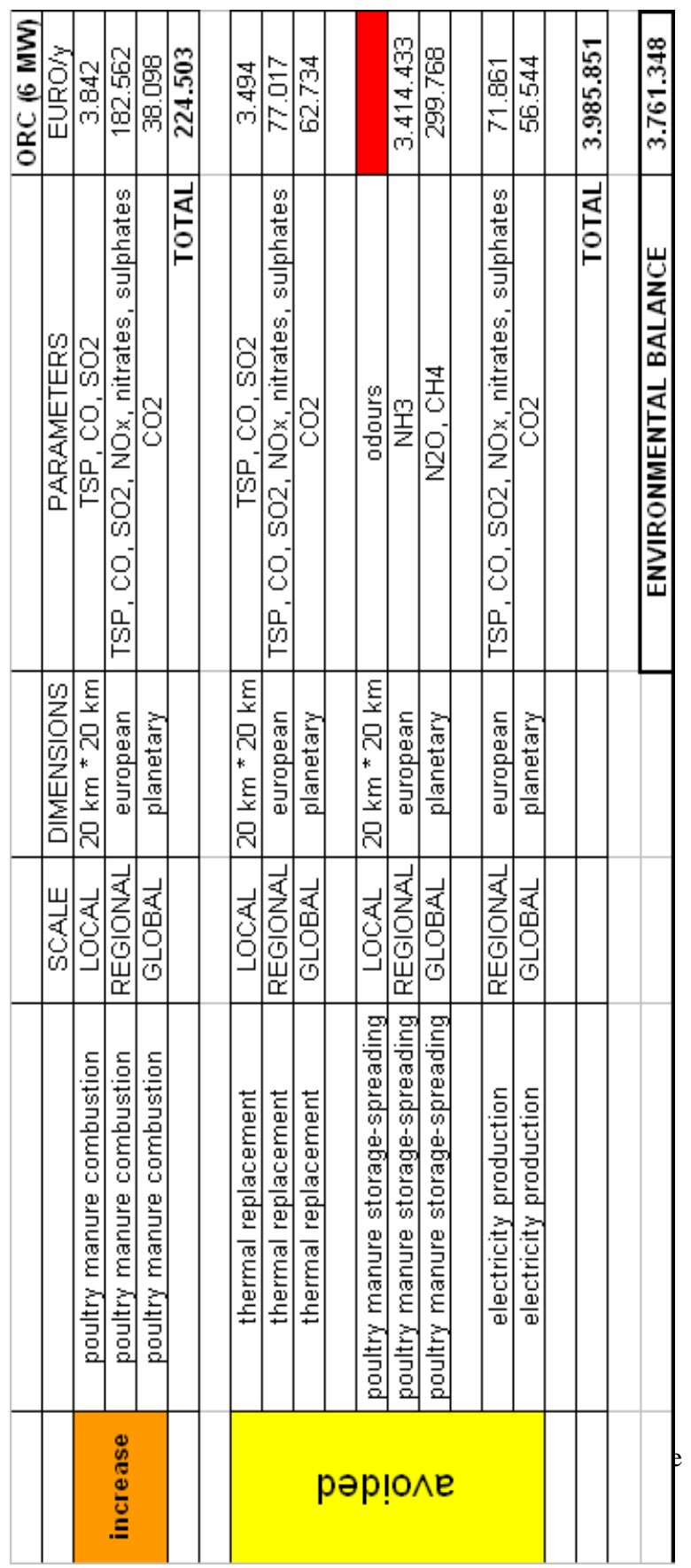

The combustion of poultry manure can bring about considerable "avoided emissions", due to the replacement of existing boilers in the case thermal energy is correctly recovered via district heating systems, the reduction of ammonia, $\mathrm{N}_{2} \mathrm{O}$ and methane releases from the storage and spreading of poultry manure and the production of electricity from a renewable fuel. In particular, ammonia 
emissions from the storage and spreading of poultry manure from laying hens are around $0,180 \mathrm{~kg}$ $\mathrm{NH}_{3} /$ head/y, $\mathrm{N}_{2} \mathrm{O}$ direct releases are around $0,047 \mathrm{~kg}$ $\mathrm{N}_{2} \mathrm{O} / \mathrm{kg}$ excreted $\mathrm{N}$, whereas methane emissions can be considered about $0,056 \mathrm{~kg} \mathrm{CH} / \mathrm{head} / \mathrm{y}$. In the case of a ORC (Organic Rankine Cycle) grate firing combustor burning $3500 \mathrm{~kg} / \mathrm{h}$ of poultry manure (6 MWth in), producing $6000 \mathrm{MWh}_{\mathrm{el}}$ and $10667 \mathrm{MWh}_{\text {th }}$ per year (the thermal energy is addressed to a district heating network), equipped with: spreader stoker, waste gas recirculation, SNCR, multi-cyclone, spray-drier (lime) and fabric filters, the environmental compatibility can be easily achieved. From the point of view of the private costs and benefits, considering a life span of 20 years substantially equivalent to the life time of the hardware and 5 years longer than the 15 years of subsidies granted in Italy, the IRR (internal rate of return) has been calculated as $13,5 \%$ associated to a NPV (net present value) of 4,7 million euros and a payback time just above seven years. The investments cost for this ORC system, including the BAT for pollutant abatements, are equivalent to 6,5 million euros. The results are indeed interesting but it's necessary to remember that the cashflow has been strongly influenced by the feed-in tariff that amounts to 13 million euros after 15 years of incentivation; last but not least, the positive cash-flow contribution coming from the district heating tariff has been set using market real average data (95 euros per thermal MWh after any form of fiscal subsidy available) for north-western Italian areas and not the lower value that may have come out if we had imposed a users charge regulatory framework (in Italy in fact district heating is nor regulated by the national energy authority, solely dedicated to electrical energy and natural gas, like in many other European countries)

The ExternE methodology [4] has been applied to the analyzed plant in order to build the overall environmental balance; the external costs have been calculated on the basis of pollutant concentration at the ground level, exposed population in the studied areas, exposureresponse functions and health impact monetization. The overall balance turns out to be strongly positive (also at the local scale) because of the large reduction of ammonia emissions that bring about a large environmental benefit as avoided secondary particles generation and GHG release.

Moreover, we didn't consider the benefit deriving from the reduction of odours and the decrease of $\mathrm{N}$ leaching towards groundwater. With regards to the odour a technique that might have been implemented is the usage of a hedonic price associated to the real estate (assuming an increase of the rents due to less odour) in the nearby areas, as sometimes shown in literature [7] or the usage of local surveys conducted to measure citizens WTP (willingness to pay) in order to get rid of the negative externality.

Figure 3 reports the details of the environmental external costs analysis at the local, regional and global scale for the studied plant.

Considering the yearly amounts of Figure 3 as occurring during the mentioned 20 years timeframe, it is possible to calculate a discounted net value of 43 million euros, mainly $(95 \%)$ due to positive externalities at regional (i.e. european) level.

\section{Conclusion}

Renewable energy plants are strongly encouraged by European legislation but their effect on air quality could be negative, in particular for compromised areas such as Northern Italy. As a matter of fact, specific emissions for NOx, PM and VOC can be larger than fossil fuel plants (in particular for NG systems) and thermal energy is often not recovered so that energy efficiency is not maximised and existing energy plants are not substituted. Moreover, energy plants such as anaerobic digesters can involve strong increase of ammonia and indirect GHG emissions that can make unsure the environmental sustainability of the technical choice. Anyway, technical solutions that can ensure the compatibility of renewable energy plants do exist but their application is hindered by the structure of public subsidies and the technical legislation that is not always suitable to manage the possible environmental impacts.

From the point of view of the integrated approach, a field where a greater attention should be paid is beyond doubts the economic regulation of the tariffs related to the heat produced in renewable energy systems connected to distribution networks (namely $\mathrm{DH}$, district heating systems): the possibility for these systems to exploit position rents might be high, especially in presence of non-uniform and non-integrated incentives framework: we believe that a regulatory framework for costs and user charges may be useful and could help to improve the penetration capacity of the technology [8]

Nonetheless in the second case study we have shown that a positive effect of subsidies is already possible: 43 million euros of positive environmental benefits vs. 13 million euros of public subsidy in 20 years (5 to 1 ratio). This brings hope to the possibility to design sound and robust environmental and energy policies in order to reach the challenging targets defined at European and international level for the next decade.

\section{References}

[1] Giugliano, M., Lonati, G., Polveri fini in atmosfera: la componente secondaria, ENERGIA 3/2005, July 2005.

[2] De Leeuw, F. A set of emission indicators for longrange transboundary air pollution, Environmental Science \& Policy, n. 5, pp. 135-145, 2002.

[3] Balsari, P., Panoramica europea ed esperienze regionali, Convegno BIOGAS E RECUPERO ENERGETICO: tra il presente e il futuro. 1-2 Aprile 2009.

[4] Bickel, P. Friedrich, R., ExternE, Externalities of energy. Methodology 2005 update. European Commission, DG XII

[5] World Bank, Regulation of Heat and electricity produced in CHP plants, 2003

[6] Terna www.terna.it, Confronti internazionali, 2007

[7] European Commission - DG Regional Policy, Guide to cost-benefit analysis of investment projects, 2008

[8] F.Becchis, G. Genon, D. Russolillo, Tariff regulation and competition as means to improve the market 
penetration of district heating and cooling systems, Proceeding of the 11th International symposium on district heating and cooling, August 31 to September 2, 2008. Reykjavik, Iceland 